\title{
Challenges Faced by Organizations in Implementing Telemedicine in Developing Countries: A Literature Review
}

\author{
Oroko Dismas Ombuya \\ School of Computer Science \\ and Bioinformatics \\ Kabarak University
}

\author{
Nicodemus Aketch Ishmael \\ School of Computer science \\ and Bioinformatics, \\ Kabarak University
}

\begin{abstract}
Telemedicine is the use of information and communication technology (ICT) to provide and support health care. It is not only limited to communication between physicians, but it can also be used in consultation, diagnosis, monitoring and even surgery. It provides a way for the masses that live in remote areas to access medical services without having to travel all the way to urban areas to seek medical attention. Most developed countries have ventured fully into telemedicine and the outcomes of the implementation of telemedicine can be felt. In developing countries, implementation has taken place as well, albeit with challenges. For instance, countries like Bangladesh are working hard towards the use of telemedicine to improve the provision of healthcare to its people. This study is as a result of the evaluation of literature to establish the challenges faced in the implementation process by developing countries. The study has pointed out challenges in telemedicine implementation that will assist developing countries to find the best ways implementing of implementing telemedicine systems.
\end{abstract}

\section{Keywords}

Telemedicine, ICT, implementation, healthcare, developing countries.

\section{INTRODUCTION}

Norish (2002) defines Telemedicine as the use of telecommunication to provide medical information and services. The definition by Norish limits Telemedicine to provision of medical information and services using Telecommunication, However, Basshur (1997) goes further in the definition and his gives more details, he posits that "Telemedicine involves the use of modern information technology, especially two-way interactive audio/video communications, computers, and telemetry, to deliver health services to remote patients and to facilitate information exchange between primary care physicians and specialists at some distances from each other."

The WHO (1997) defines it as "the delivery of health-care service, whereby distance is a critical factor, by health care professionals using information and communication technologies for the exchange of valid information for diagnosis, treatment and prevention of disease and injuries, and for continuing education of health care providers as well as research and evaluation, all in the interest of individuals and their communities."

Technology uptake has created immense possibilities for both doctors and patients, computers are used in the medical field to send live videos, sound and high resolution images to distant locations as well as for examining patients in clinics that are in remote areas.

The implementation of telemedicine is not only a challenge in developing countries, but also in developed countries. However, having things done right from the onset of the implementation can lead to a successful implementation. Peter (2005) argues that successfully developing telemedicine systems is primarily about effective change management within an already rapidly changing health-care environment.

This study seeks to address challenges faced by those who have tried to implement telemedicine in developing countries through a review of literature related to telemedicine implementation. The researcher believes the findings of this study will go a long way in mitigating problems and myriad of challenges that developing countries face in their efforts to give quality medical services to their masses.

\section{THE HEALTHCARE SITUATION IN DEVELOPING COUNTRIES}

Challenges that have to do with constrained resources in the health sector are becoming synonymous with developing countries. Lack of medical equipment and medicine are some of the issues that developing countries are still fighting. The effects of brain drain do not make the situation any better. It is estimated that the number of international immigrants increased from 75 million in 1960 to around 190 million in 2005. The issue of brain drain affects even the medical field harder. It has become a concern of scholars that medical professionals from developing countries are moving to developed countries in masses. In Africa alone, where health needs and problems are greatest, 2001 report indicate that around 23000 qualified academic professionals emigrate annually (International Herald trib., 2001). Weiner, R. et al (1998) states that Information from South African medical schools suggests that a third to a half of its graduates immigrate to the developed world. The loss of nurses has been even more extreme - for example, more than 150000 Filipino nurses (Corcega T.et al ,2000) and 18000 Zimbabwean nurses (Mangwende B., 2001) work abroad. A recent report from the United Kingdom estimated that $31 \%$ of its doctors and $13 \%$ of its nurses are born overseas. With such statistics that are not even a reflection of the recent past then it's a clear indication that there is a serious crisis in developing countries. This situation now leads to a concentration of the few medical personnel that are available to urban areas and thus forcing masses to jostle for the few who are available after having to travel miles away to receive that much needed attention. 
The reports in the World Health organization paint a situation that is not good in terms of the number of medical practitioners in the African region. In a report that divides the world into six regions (African region, Region of the Americas, South-East Asia region, European region, Eastern Mediterranean region and western pacific Region), Africa seems to be having the least of the medical practitioners compared to the other regions. Some regions like the Americas and European region that have the highest population seem to be having immigrant medical practitioners most of whom are from the African region. This is not only a worrying trend, but one that spells doom for Africa and indeed most of the developing countries.

With this in mind, telemedicine is not only going to assist in augmenting but it will be a panacea, and indeed a necessity to make it possible for patients to access cheap and quality medical attention and like we have mentioned earlier on, a healthy economy is a prosperous economy. There is a relationship between health and economy for a nation that can't be wished a way, but instead be given a very special attention.

Table 1: Source: Who, 2012:130

\begin{tabular}{|c|c|c|c|c|c|}
\hline WHO Region ${ }^{*}$ & $\begin{array}{l}\text { Number of } \\
\text { doctors } \mid 0,000\end{array}$ & Density & $\begin{array}{c}\text { Number of } \\
\text { nurses and } \\
\text { midwives } \mid 0,000\end{array}$ & Density & $\begin{array}{l}\text { Total density } \\
\text { doccors, nurses } \\
\text { and midwives }\end{array}$ \\
\hline African Region & $\mid 18,621$ & 2.2 & 467,487 & 9.0 & $\| .2$ \\
\hline Region of the Americas & $1,555,428$ & 20.0 & $4,749,397$ & 72.5 & 92.5 \\
\hline South-East Asia Region & 901,006 & 5.6 & $1,736,755$ & 10.9 & 16.4 \\
\hline European Region & $2,942,286$ & 33.2 & $5,766,646$ & 65.0 & 98.2 \\
\hline $\begin{array}{l}\text { Eastern Mediterranean } \\
\text { Region }\end{array}$ & 626,923 & 10.9 & 856,744 & 15.6 & 26.5 \\
\hline Westem Pacific Region & $2,507,843$ & 14.8 & $3,|| 2,2,2 \mid$ & 18.4 & 33.3 \\
\hline
\end{tabular}

\section{CHALLENGES FACED BY ORGANIZATIONS IN IMPLEMENTING TELEMEDICINE IN DEVELOPING COUNTRIES}

Wootton et al (2006) posits that the rate of telemedicine deployment in developing countries has gone down or even stalled compared to developed countries. According to the figure below, continents with the most developing countries have the least telemedicine initiatives.

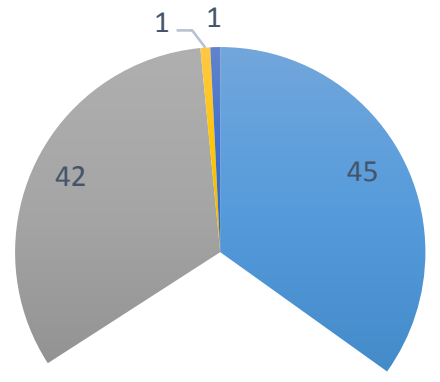

40

US Europe Australia Africa Asia

Telemedicine deployment globally (Redrawn from data in wootton et al., 2006)

Some of the challenges facing telemedicine implementation in developing countries have been discussed below.

\section{FINANCIAL CHALLENGES}

Implementation of telemedicine systems in developing countries has been hampered by lack of enough financial allocation. A few of those initiatives in existence according to Heinzelmann et al. (2005) are mainly grant supported and are and will continue facing the challenge of sustainability. Since telemedicine projects are expensive to implement (Wootton et al., 2005; Khan et al., 2007), the source of funding for these projects should be greatly taken into account before the actual implementation for longevity (LeRouge et al., 2010). The cost of acquisition and maintenance of equipment for telemedicine is so high which does not help either.

To enable developing countries to import medical devices used in telemedicine applications, World Trade Organization (1996) which deals with global rules of trade between nations concluded that all telemedicine devices to be used in developing countries be reduced to zero tariff as well as having duties and charges bound at zero.

\section{ADMINISTRATION RELUCTANCE TO ACCEPT CHANGE}

For success of any project, support from the administration is paramount, without which no much will be done. According to Jennet et el. (2009) administrative readiness to accept change facilitates the adoption of new technology. This according to Bashshur (1999) has been necessitated by the fear that telemedicine will replace the physician or relegate him to a less important role. Again, Christensen et al. (2000) posits that organizations providing expensive healthcare tend to fight simpler healthcare innovations since they threaten their livelihoods.

\section{LACK OF SUFFICIENT LITERATURE}

According to Clark and Goodwin (2010), literacy levels, awareness and understanding of the benefits of a new technology to be adopted has a great impact on the degree of acceptance of the technology by the adopters. However, Wootton et al., (2005) claims that low levels of literacy has 
excluded the majority of communities in developing countries from attempting to adopt new technologies.

\section{INTERNET PENETRATION MOBILE TELEPHONY UPTAKE}

AND

There is a direct relationship between the success or failure technology innovation adoption and Internet penetration and mobile telephony uptake. Non-availability to high speed internet connections in some locations is a serious hindrance to achieving telemedicine coverage

According to statistics from the ITU Telecommunication Development Bureau, ICT facts \& figures (2015), there is a clear indication that internet penetration and mobile uptake is very low in those continents that have the most number of developing countries like Africa and Asia, the graphs below give a glimpse of how things are.

\section{Percentage of households with internet access \\ 1. Europe, 2. Americas, 3. $\mathrm{CIS}$, 4. Arab states, 5. Asia \& Pacific, 6. Africa}

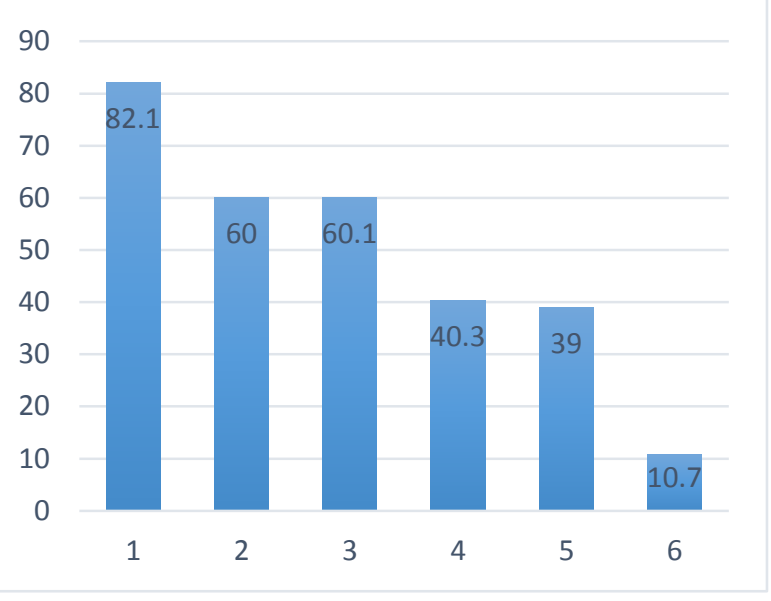

Source: Redrawn from the ITU Telecommunication Development Bureau, ICT facts \& figures (2015)

Subscriptions to Internet services especially fixed broadband subscriptions which would have helped spur growth in implementation of telemedicine is wanting in developing and least developed countries according to the ITU 2005 report. They go on to say that Fixed-broadband

uptake remains slow in developing countries and particularly in LDCs, where penetration rates are now at $7 \%$ and less than $1 \%$, respectively.
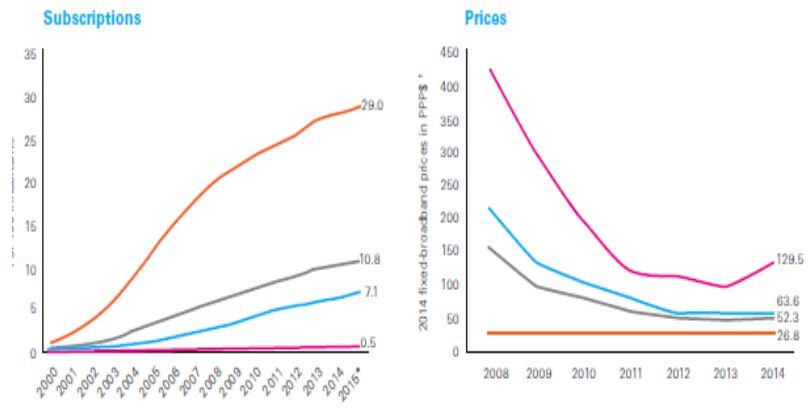

Source: Redrawn from the ITU Telecommunication Development Bureau, ICT facts \& figures (2015)

\section{CONCLUSION AND RECOMMENDATIONS}

The potential of telemedicine systems to transform medical care practice has been recognized over the past decades including their ability to enhance healthcare delivery and facilitate decision-making processes. Most of the challenges facing the implementation of telemedicine are surmountable with determination from stake holders. It is high time the developing world re-thinks its commitment towards giving better health care to its masses by embracing innovation and enhancing financing towards such initiatives as telemedicine and generally ICT in solving human problems. Partnerships with people and nations of good will also help in unleashing the potential that is in telemedicine and generally technology to improve human lives. If this is taken to consideration then there is hope for developing countries.

\section{REFERENCES}

[1] Bashshur R, Sanders J, Shannon G. (1997). Telemedicine Theory and Practice. Springfield, IL: Charles C Thomas Publisher Ltd, p. 9.

[2] Christensen, C., Bohmer, R. and Kenagy, J. (2000) 'Will Disruptive Innovations Cure Health Care?', Harvard Business Review 78(5), pp. 102-117.

[3] Corcega T, Lorenzo M, Yabes J, sde la Merced B, Vales K. (2000) Nurse supply and demand in the Philippines. The UP Manila,;5:1-8.

[4] Goodwin, N. (2010) 'The state of telehealth and telecare in the UK: Prospects for integrated care', Journal of Integrated Care, 18(6), pp.3-10.

[5] Jennett, P., Yeo, M., Pauls, M. and Graham, J. (2009) 'Organisation readiness for telemedicine: implications for success and failure', Journal of Telemedicine and Telecare, 9(2), pp. 27-30.

[6] Khan, M., Varghese, P., Wootton, R. and Gray, L. (2007) 'Successes and failures in assessing cognitive function in older adults using video consultation', Journal of Telemedicine and Telecare, 13(3), pp. 60-62.

[7] LeRouge, C., Tulu, M. and Forducey, P. (2010) 'The business of telemedicine: Strategy primer', Journal of telemedicine and e-health, 16(8), pp. 898-909.

[8] Norris, A. C. (2002). Essentials of telemedicine and telecare, John wiley \& sons. Ltd.

[9] Weiner R, Mitchell G, Price M. (1998)Wits medical graduates : where are they now ?. S Afr J Sci;94:59-63. 
[10] Wootton, R., Craig, J. and Patterson, V. (2006) Introduction to Telemedicine. 2nd edn. London: Royal Society of Medicine.

[11] Wootton, R., Jebamaniw, L. and Dow, S. (2005) 'Ehealth and the Universitas 21 organisation: 2 . Telemedicine and underserved populations', Journal of Telemedicine and Telecare, 11 (5), pp. 221-224.
[12] World Trade Organisation (1996) Information and Technology Agreement. Available at: www.wto.org/english/tratop_e/inftec_e/itaintro_e.htm (Accessed: 06/10/2016)

[13] https://www.itu.int/en/ITUD/Statistics/Documents/facts/ICTFactsFigures2015.pdf (Accessed : 12/10/2016) 